\title{
EEN MISLUKTE OPKNOPING TE BRUGGE IN 1613. MIRAKEL OF TOEVAL ?
}

\section{J. MONBALLYU ${ }^{\circ}$}

Op 6 februari 1613 werd Pieter van Wesemaele uit Lokeren, 24 jaar oud en kleermaker van beroep, door de Brugse stadsschepenen tot de galg veroordeeld ${ }^{1}$. Volgens het toenmalige strafrecht was dit meer dan verantwoord. Pieter van Wesemaele had immers tot tweemaal toe een huisdiefstal met verzwarende omstandigheden gepleegd en was bovendien begonnen met het voorbereiden van een derde nog veel grotere huisdiefstal. De eerste diefstal vond plaats te Gent bij een weduwe die hem uit vriendschap voor zijn ouders een tijdlang had geherbergd nadat hij wegens een vechtpartij, waarbij een voerman zwaar werd gekwest, uit het Land van Waas had moeten vluchten. Ondanks deze gastvrijheid had hij aldaar in de slaapkamer van de weduwe een koffer met zijn handen opengebroken en er minstens dertig ponden groten in goud weggenomen. De tweede huisdiefstal had hij gepleegd in Brugge bij niemand minder dan de schout die hem als knecht had tewerkgesteld. Bij deze hoge Brugse gerechtsofficier, die onder meer belast was met het vervolgen van alle misdrijven in de stad Brugge, had hij uit een kast twaalf ponden groten gestolen. Hiertoe had hij vooraf de kastsleutel weggenomen van de plaats waar zijn meester hem gewoonlijk bewaarde. Bovendien had hij samen met een andere knecht het plan opgevat om de schout nog van een veel grotere geldsom te beroven, dit door het kraken van zijn geldkoffer. Om dit plan te kunnen uitvoeren had hij reeds van de voordeur van de schout een sleutel laten bijmaken en was hij begonnen met het maken en afstellen van een valse sleutel van diens geldkoffer via een wasafdruk die zijn medeplichtige hem

- Prof. KUL, Faculteit van de Rechtsgeleerdheid ; Melkweg 39, 8720 Kuurne.

1. BRUGGE, STADSARCHIEF, 192 (Verluydboeck 1611-1676), f. 16r-19'. 
had bezorgd. Het plan lekte echter uit en Pieter van Wesemaele werd samen met zijn medeplichtige opgepakt en tot de galg veroordeeld. Gezien de herhaling, het misbruik van vertrouwen en de sociale positie van het slachtoffer was dit in die tijd een meer dan normale straf ${ }^{2}$. Als dusdanig zou Pieter van Wesemaele dan ook niet de geschiedenis zijn ingegaan, ware het niet dat zijn executie verre van een leien dakje liep en uiteindelijk mislukte.

Om aan Pieter van Wesemaele's opknoping, die van zijn medeplichtige en die van twee valsmunters een exemplarisch karakter te geven $^{3}$, besloot de Brugse stadsmagistraat deze opknopingen samen in één spektakel op de Burg van Brugge te laten plaatsvinden. Inderhaast werd aldaar een galg opgericht waaraan de vier veroordeelden één na één zouden worden opgeknoopt en werd er in de stad overal kond gedaan van de geplande strafvoltrekkingen. Tuk op sensatie stroomde het volk van overal toe naar het Burgplein zodat bij de aanvang van de executies de Burg zwart stond van het volk ${ }^{4}$. Pieter van Wesemaele werd door het lot aangewezen om als eerste te worden opgeknoopt. Nadat hij ten aanzien van de prior van de Predikheren zijn biecht had uitgesproken en met hem een rozenkrans had gebeden, werd hij voorgeleid en door de beul via een ladder naar de bovenkant van de galg gebracht. Aldaar werd hem de koord om de hals gelegd en werd hij vervolgens van de ladder afgeduwd. Terwijl hij aldus tussen hemel en aarde hing, duwde de beul hem met zijn voeten op het lichaam teneinde hem met enkele stoten te wurgen en aldus zijn doodsstrijd zo kort mogelijk te

2. L. Th. MAES, Vijf eeuwen stedelijk strafrecht, Antwerpen, 1947, p. 200 ; F. VAN HEMELRIJCK, De criminaliteit in de ammanie van Brussel van de late middeleeuwen tot het einde van het ancien régime (1404-1789), Brussel, 1981, p. 186 ; A. LAINGUI en A. LEBIGRE, Histoire du droit pénal, I, Parijs, s.d., p. 183-186 ; J. CLARUS, Sententiarum receptarum, Liber Quintus, Venetië, 1601, § Furtum, 9 (p. 20) ; J. KOHLER en W. SCHEEL, Die Carolina und ihre vorgangerinnen, Halle, 1900, p. 86 en 87 ; J. DE DAMHOUDERE, Practijcke ende handbouck in criminele zaeken, Leuven, 1555 (Anast. druk, Roeselare, 1981), p. 138 ; A. GOMEZ, Commentariorum variarumque resolutionum iuris civilis communis et regii, tomi tres, Antwerpen, 1615 , p. 488.

3. De behoefte om een voorbeeld te stellen wordt uitdrukkelijk in het vonnis vermeld : «...in exemple van andere...».

4. Zie verder in bijlage de vorstelijke genadebrief : «...overzulcx het ghemeeinte, dwelcke in zeer groote ghetalle was aensiende de justicie ende het recht dat men over den suppliant was doende...». 
maken ${ }^{5}$. Dit stoten was er echter duidelijk teveel aan, want plotseling brak de koord middendoor waardoor Pieter van Wesemaele hardhandig op de onderliggende kasseien terechtkwam, zwaar aan het hoofd werd gekwetst en bewusteloos bleef liggen. Daar de beul evenwel vaststelde dat Pieter ondanks alles nog tekenen van leven vertoonde, haastte hij zich tot groot ongenoegen van het volk, dat spontaan om genade riep, om hem terug naar de ladder te slepen en hem aldaar verder te wurgen tot hij geen teken van leven meer gaf en alle aanwezigen hem dood achtten. Teneinde het volk te bedaren werd hij vervolgens zo vlug mogelijk op een lijkbaar gelegd en naar het kerkhof van Sint-Donaas afgevoerd. Aldaar wierp men hem zonder meer in een inmiddels klaargemaakt graf. Daar men echter van plan was om in diezelfde put ook de drie andere nog op te knopen misdadigers te begraven, liet men de put nog een tijdlang openliggen. Gelukkig voor Pieter, want na enige tijd begon hij zich opnieuw te bewegen zodat men kon vaststellen dat hij nog steeds niet het tijdelijke voor het eeuwige had verwisseld. Onmiddellijk werd hij uit de grafput gehaald en binnengedragen in een voorkamer van de Sint-Donaaskerk waar hem de nodige geneeskundige zorgen werden verstrekt. De Brugse stadsmagistraat, die intussen op de hoogte was gebracht, eiste echter dat Pieter van Wesemaele onmiddellijk naar de Burg zou worden teruggebracht teneinde hem voor een derde en wellicht definitieve maal te laten executeren. Zich steunend op zijn kerkelijke immuniteit weigerde het kapittel van Sint-Donaas evenwel om hierop in te gaan 6 . Pieter van Wesemaele bleef aldus in de voorkamer van de Sint-Donaas liggen alwaar hij na drie dagen opnieuw tot bewustzijn kwam. Toen men hem van het gebeurde op de hoogte bracht, verklaarde hij onomwonden te geloven dat hij werd gered door O.L.-Vrouw tot wie hij tot op het allerlaatste moment zou hebben gebeden en in wiens handen hij zijn lot had gegeven.

Tegenover dergelijke al dan niet miraculeuze redding of wonderbare

5. BRUSSEL, RIJKSARCHIEF, Rekenkamer, 13790, Schoutrekening Brugge 1613-1616, f. $15^{\vee}$ : «Ledict XVe janvyer 1613 Pierre Wesemale fust pendu et non estranglé d'aultant que l'officier faysant grand effort de ses pieds sur son corps pour luy racourcyr la peyne, le hard rompyst et tomba par terre reputé pour mort...».

6. BRUGGE, BISSCHOPPELIJK ARCHIEF, Register A 67, f. 174 ${ }^{\mathrm{r}}$ : «....quem magistratus restitui petivit ut justitia adimpleretur, sed domini de capitulo restituere noluerunt in preiudicium immunitatis ecclesiasticae». 
gebedsverhoring voelde blijkbaar iedereen zich onzeker. Besloten werd om voor Pieter genade aan te vragen bij de aartshertogen Albrecht en Isabella. Deze werd bekomen op 28 februari van datzelfde jaar. Zich steunend op het feit dat Pieter van Wesemaele hoe dan ook wel de bittere dood zou hebben gesmaakt zodat de justitie zich voldaan kon achten, het feit dat de Brugse bevolking spontaan om genade had verzocht en het feit dat Pieter er rostvast scheen in te geloven dat hij door O.L.-Vrouw werd gered, werden al Pieters eerdere misdrijven kwijtgescholden. Aan alle Brugse en andere gerechtsofficieren en rechters werd verboden Pieter nog te vervolgen en te veroordelen voor de gepleegde en geplande huisdief stallen en zijn vechtpartij in het Land van Waas. Zowel de Brugse schepenen als het kapittel van Sint-Donaas klasseerden deze zaak door de genadebrief te registreren ${ }^{7}$. Wel lieten de Brugse kanunniken Pieter van Wesemaele op 6 maart 1613 nog eens plechtig voor hen verschijnen teneinde hem aan te sporen voortaan als een goed christelijk mens te leven en hem er wellicht op te wijzen dat hij in de toekomst niet al te veel meer van dergelijke miraculeuze reddingen moest verwachten ${ }^{8}$. Of Pieter van Wesemaele hiermee rekening heeft gehouden is ons niet bekend.

Uit deze toch wel merkwaardige gebeurtenissen kunnen nu enkele interessante conclusies worden getrokken. Vooreerst tonen zij aan dat tot in het begin van de $17 \mathrm{de}$ eeuw bij een groot deel van de bevolking nog steevast de overtuiging leefde dat bij het mislukken van een executie de veroordeelde niet een tweede maal mocht worden terechtgesteld. Deze eeuwenoude gewoonte ${ }^{9}$ steunde, in tegenstelling met wat de genadebrief d.d. 18 februari 1613 en een aantal latere auteurs ${ }^{10}$ willen doen geloven, niet op de overtuiging dat God al dan niet door bemiddeling van zijn heiligen in de strafrechtpleging rechtstreeks kon tussenkomen, maar op een bij het volk van die tijd nog ruim verspreid magisch bewustzijn. Wie het volksleven

7. Ibidem, f. $175^{\mathrm{v}}-176^{v}$; BRUGGE, STADSARCHIEF, 192 (Verluydboeck 16131676), f. $17^{\mathrm{r}}-19^{\mathrm{r}}$.

8. BRUGGE, BISSCHOPPELIJK ARCHIEF, Register A 67, f. 175".

9. W. SCHILD, Alte Gerichtsbarkeit. Vom Gottesurteil bis zum Beginn der modernen Rechtsprechung, München, 1980, p. 20.

10. H. HATTENHAUER, Das Recht der Heiligen (Schriften zur Rechtsgeschichte Heft 12) Berlijn, 1976, p. 17-19. 
in het verre of meer nabije verleden bestudeert, kan niet voorbijgaan aan de vaststelling dat velen soms tot in de 20ste eeuw leefden met een primitieve of magische mentaliteit die gekenmerkt was door ${ }^{11}$ :

- vooreerst een grote innerlijke verbondenheid van de mens met alles wat hij rondom zich in de wereld aantrof en een sterk ordebewustzijn. Niet alleen de dieren en de planten, maar ook de grond, de rivieren, de meren, de zee, de zon, de maan, de sterren, de bergen en allerlei andere natuurverschijnselen werden geacht met de mens mee te leven en op zijn daden te reageren. Samen werden ze geacht bepaald te worden door allerlei geheimzinnige en onbepaalde bovennatuurlijke krachten die niet alleen ziekte en dood, geluk of ongeluk, maar ook de werking van de natuurelementen bepaalde. In deze wereldbeschouwing kon niet alleen elke verstoring van de orde door de gepaste tegenmaatregel worden hersteld, maar was bovendien niets toeval, ook het ogenschijnlijk meest onbegrijpelijke. Wat er ook gebeurde, het had steeds een zin.

- ten tweede het vrijwel geheel ontbreken van transcendent of abstract denken. De aanvaarding van een mysterieuze en onzichtbare werkelijkheid leidde ertoe dat natuur en bovennatuur in hetzelfde vlak kwamen te liggen. Dit impliceerde een onkritisiche houding die veel meer door gevoel en wil dan door verstand en redenering werd beheerst. In dit prelogisch denken legde men zich vlug neer bij de feiten omdat zij nu eenmaal zo waren.

- ten derde speelde de gemeenschap een grote rol in het leven van het individu. De gewone man redeneerde immers niet volgens eigen denkgewoonten maar volgens die van de groep. Logisch denken was in zekere zin asociaal. Oorzaken en hulpmiddelen worden niet gezocht in gebieden die men niet kende, zoals bij voorbeeld de wetenschap, maar in de door de groep aanvaarde

11. Over deze magische mentaliteit en zijn kenmerken raadplege men : K. THOMAS, Religion and the decline of Magic. Studies in popular beliefs in sixteenth and seventeenth century England, Londen, 1971; R. MUCHEMBLED, Sorcellerie, culture populaire et christianisme au XVIe siècle, principalement en Flandre et en Artois, Annales E.S.C., jan-févr., 1973, p. 264-284 ; ID, Culture populaire et culture des élites dans la France moderne (XVe - XVIIe siècle). Essai, Parijs, 1978 ; R.L. WAGNER, Sorcier et Magicien. Contribution à l'histoire du vocabulaire de la Magie, Parijs, 1939 ; J. VAN HAVER, Nederlandse incantatieliteratuur. Een gecommentarieerd compendium van de Nederlandse bezweringsformules, Gent, 1964, p. 38-42 ; ID, Volksgeneeskunde, (Catalogus tentoonstelling A.S.L.K.), Brussel, 1981, p. 17-23. 
stellingen. Zelfs indien bepaalde gewoonten en gebruiken in strijd waren met godsdienstige of burgerlijke voorschriften, dan nog voelde de enkeling zich bij het toepassen ervan volkomen gerechtvaardigd in zijn optreden omdat hij handelde en dacht zoals iedereen. In feite besliste de gemeenschap voor het individu dat slechts mocht handelen op de wijze die paste in het traditionele gedragspatroon van de gemeenschap.

Dit magisch bewustzijn nu was tot diep in de 17 de eeuw ruim verspreid bij de bevolking. Auteurs zoals J. Delumeau' ${ }^{12}, \mathrm{~K}$. Thomas $^{13}$, R. Muchembled ${ }^{14}$ hebben de mythe van de christelijke middeleeuwen de grond ingeboord. Tot diep in de $17 \mathrm{de}$ eeuw was de grote meerderheid van de bevolking, en dan in het bijzonder de lagere klassen, doordrongen van deze animistische mentaliteit waarin de magie fungeerde als een tekensysteem dat toeliet psychologisch te overleven in een wereld die gekenmerkt was door permanente onzekerheden ${ }^{15}$. Deze magische mentaliteit biedt een verklaring niet alleen voor het voorkomen van talrijke heksenprocessen in de loop van de $16 \mathrm{de}$ en $17 \mathrm{de}$ eeuw, maar ook veel ander strafrechterlijk optreden in de middeleeuwen en het begin van de nieuwe tijd ${ }^{16}$. Onder meer wordt hierdoor duidelijk waarom allerlei rituele gebruiken bij de uitvoering van de doodstraf die reeds bij de Germanen te vinden waren ook nog tot in de $16 \mathrm{de}-17 \mathrm{de}$ eeuw werden aangewend. In tegenstelling met wat $\mathrm{K}$. von $\mathrm{Amira}^{17}$ en velen na hem ${ }^{18}$ hebben beweerd, waren dit geen relicten van Germaanse opofferingsstraffen aan bepaalde goden, maar rituelen die ertoe strekten het door het misdrijf verbroken magische evenwicht te herstellen (Wiedergutma-

12. J. DELUMEAU, Le catholicisme entre Luther et Voltaire, Parijs, 1979, p. 237-258.

13. K. THOMAS, a.w.

14. R. MUCHEMBLED, Culture populaire, p. 79-135.

15. H. SOLY, De grote heksenjacht in West-Europa 1560-1650. Een voorlopige balans, Volkskunde, LXXXII (1981), p. 107.

16. W. SCHILD, a.w., p. 65-76.

17. K. VON AMIRA, Die germanischen Todesstrafen, München, 1922.

18. L. Th. MAES, a.w., p. 381-382, 391 en 396 ; R.C. VAN CAENEGEM, Geschiedenis van het strafrecht in Vlaanderen van de XIe tot de XIVe eeuw, Brussel, 1954 , p. 18 en $172-173$. 
chungszauber) of de verbreking ervan in de toekomst te voorkomen (Reinigungs- und Abwehrzauber) ${ }^{19}$.

Ook de eeuwenoude gewoonte dat bij het mislukken van een executie de veroordeelde niet een tweede maal mocht worden terechtgesteld, dient in deze magische contekst te worden teruggeplaatst indien men ze wil begrijpen. Deze gewoonte steunde niet zoals velen hebben beweerd ${ }^{20}$ op het voortleven van het heidense geloof dat de Godheid door het mislukken van de executie had aangetoond dat het hem aangeboden offer niet welgevallig was, maar op het alsdan nog zeer ruim verspreide magische bewustzijn, waarin zoals gezegd niets toeval was en ook het ogenschijnlijk meest onredelijke vrijwel kritiekloos werd aanvaard. In deze magische mentaliteit hoefde het breken van een koord of zwaard bij een executie geen nadere verklaring. Door het opknopen of het toeslaan met het zwaard waren de nodige rituele gebaren gesteld om de door het misdrijf verstoorde orde te herstellen. Waarom de executie uiteindelijk mislukt was kon in dit geloof niet worden achterhaald of ten hoogste alleen aan de werking van allerlei onbepaalde bovennatuurlijke krachten worden toegeschreven. Deze waren noch voor zintuigelijke waarneming, noch voor het verstand vatbaar en dienden dan ook niet te worden verklaard. De misdadiger was uiteindelijk aan de dood ontsnapt en zo moest het ook maar blijven. Men legde zich gewoon neer bij de feiten zonder ze nader te analyseren of er kritiek op te leveren.

In de middeleeuwen, waar deze magische mentaliteit zowat algemeen was, had alleen de Kerk het moeilijk met deze onkritische houding. Daar ze evenwel goed besefde dat er aan deze eeuwenoude en sterk ingewortelde gewoonte niet te tornen viel, zocht zij naar een behoorlijke verklaring om ze te legitimeren. Deze werd dan gevonden door een beroep te doen op het procédé bij uitstek van die tijd, namelijk de theorie van een mirakel. Door het breken van de koord zou God, al dan niet na bemiddeling van één van zijn heiligen, hebben aangetoond dat hij zich over de misdadiger had erbarmd en dat derhalve zijn dood niet meer wenselijk was. Daar nu volgens de

19. Zie vooral het werk van B. REHFELDT, Todesstrafen und Bekehrungsgeschichte. Zur Rechts- und Religionsgeschichte der germanischen Hinrichtugsbräuche, Berlijn, 1942, p. 114-137 en 145-155.

20. H. HATTENHAUER, a.w., p. 17-18. 
Kerk alle wereldlijke justitie uiteindelijk zijn grondslag in de goddelijke wil vond, mocht de misdadiger niet een tweede maal worden terechtgesteld. Deze theorie, die in meerdere laat-middeleeuwse teksten terug te vinden is en ook aanleiding was tot het maken van meerdere kunstwerken ter ere van de heilige die bij God zou hebben bemiddeld ${ }^{21}$, was in feite niets anders dan een christianisering van een magische gewoonte. Via de theorie van het mirakel werd een aloude «heidense» praktijk in het christelijk normenbestand opgenomen en aanvaardbaar gemaakt en kon deze aldus door de middeleeuwen heen blijven verder bestaan.

Het spreekt vanzelf dat de Romeinsrechtelijk geschoolde juristen die vanaf de 14de-15de eeuw het middeleeuws strafrecht van binnenuit wensten te moderniseren en te rationaliseren, eveneens moeilijk met deze gewoonte overweg konden. Sommigen van hen zoals een J. de Belvisio, J. Clarus, A. Bocerus, J. Harpprecht pleitten dan ook voor haar radicale afschaffing. Duidelijke veroordelingen tot een doodstraf waren volgens hen niet voor interpretatie vatbaar. Bovendien diende volgens deze auteurs bij het mislukken van een executie steeds vermoed te worden dat dit gebeurd was ofwel door het toedoen van de duivel ofwel door het toedoen van de beul die zich had laten omkopen of een nalatigheid had begaan. In dergelijke omstandigheden een misdadiger aan het hem verdiende lot laten ontsnappen leek hen dan ook vanuit strafpolitiek oogpunt niet heilzaam ; weet hebbende van deze mogelijkheid zouden de verwanten van de veroordeelde te sterk worden aangespoord om de beul om te kopen en aldus een nieuw misdrijf te begaan ${ }^{22}$. Anderen daarentegen zoals een L. de Penna, P. Decius, P. de Puteo, A. Tiraquellus, M. van Wesembeke, A. Gomez, B. Chassanaeus - om maar de voornaamste te noemen - verdedigden nochtans het behoud van deze beslissende verschoningsgrond. Als argument lieten zij gelden dat in dergelijke gevallen een mirakel niet uitgesloten was en in geval van twijfel het altijd beter was een schuldige vrij te spreken dan een onschuldige te straffen. Wel stelden sommigen van hen als voorwaar-

21. Ibidem; W. SCHILD, a.w., p. 20.

22. Een samenvatting van de standpunten van deze auteurs vindt men bij J. DÖPLER, Theatri poenarum, suppliciorum et executionum criminalium..., Leipzig, 1697, p. 247-248 en B. Carpzov, Practica nova imperialis saxoniae rerum criminalium, Leipzig, 1709, p. 276-277. 
de dat men voldoende had nagegaan dat er van bedrog of nalatigheid bij de beul geen sprake was. Het feit dat de veroordeelde steeds had volgehouden dat hij onschuldig was en vóór de executie op Gods hulp of van die van zijn heiligen een beroep had gedaan, leverde volgens sommige van hen het vermoeden van een mirakel ${ }^{23}$. Een derde categorie van auteurs tenslotte, met aan het hoofd de befaamde B. Carpzov, stond een soort tussenoplossing voor : de veroordeelde diende niet een tweede maal te worden geëxecuteerd maar voor eeuwig verbannen uit het land. Volgens deze auteurs kon de strafrechter steeds verzachtende omstandigheden in acht nemen ; de pijn en smarten die de veroordeelde door de mislukte executie onbetwistbaar had opgelopen rechtvaardigen de omzetting van de doodstraf in de onmiddellijk lagere straf zijnde de eeuwige verbanning. Als dusdanig werd tevens de ergernis vermeden die door het zonder meer vrijlaten van de veroordeelde bij slachtoffers van het misdrijf of anderen zou kunnen ontstaan. Tenslotte diende volgens Carpzov in dergelijke gevallen de beul voor minstens één jaar uit zijn ambt te worden ontzet. Hieruit blijkt nogmaals dat hij niet meer geloofde aan de mogelijkheid van een mirakel ${ }^{24}$.

Hieruit moge duidelijk zijn dat zowel de Brugse stadsmagistraat als de Brugse kanunniken in 1613 in de rechtsleer argumenten konden vinden voor hun stellingname. Om uit deze patstelling te geraken deden ze een beroep op de Aartshertogen. Deze beslisten uiteindelijk in het voordeel van de Brugse kanunniken. In hun genadebrief vinden wij de klassieke argumenten voor de vrijlating : het vermoeden dat het om een mirakel kon gaan en het feit dat Pieter van Wesemaele door de mislukte executie reeds meer dan genoeg leed had ondergaan. Het spontane verzoek van de Brugse volksmassa leverde een bijkomend argument op.

Het verlenen van deze remissie- of genadebrief leidt ons tot een tweede vaststelling in verband met het oude strafrecht. Meerdere auteurs hebben reeds het onmenselijke en wreedaardige karakter van het oude strafrecht benadrukt. Niet alleen strafpolitieke (afschrikking van derden) maar ook juridisch-politieke doeleinden (het

23. Ibidem. Zie ook : Le «De poenis temperandis» de Tiraqueru (1559), Introduction, traduction et notes par A. Laingui, Parijs, 1986, p. 223.

24. Ibidem. 
in het zadel houden van het monarchale en aristocratische gezag) zouden hierbij een rol hebben gespeeld ${ }^{25}$. En inderdaad, wanneer men de strafvonnissen van de late middeleeuwen en de nieuwe tijd onderzoekt kan men niet anders dan ertoe besluiten dat het soms zielig en hallucinant spektakel waartoe sommige openbare strafvoltrekkingen aanleiding hebben gegeven, werd veroorzaakt door de nadruk die in de wetgeving en de rechtsleer werd gelegd op het exemplarische of algemeen preventieve karakter van de straffen. Wil men echter de strafpolitiek van het oud regime goed begrijpen, dan moeten ook de vorstelijke genadebrieven in deze studie worden betrokken. Deze werden voor bepaalde misdrijven zoals eenvoudige doodslag, slagen en verwondingen zeer gemakkelijk verleend en hebben dan ook onbetwistbaar de scherpe hoeken van het toenmalige strafrechtssysteem afgerond. Vooral voor de studie van de verschoningsgronden zoals noodweer, noodtoestand, dronkenschap, krankzinnigheid, overmacht en allerlei verzachtende omstandigheden, vormen zij een belangrijke, om niet te zeggen de belangrijkste bron voor de studie van het oude strafrecht ${ }^{26}$. Helaas werden zij voor de Nederlanden zogoed als nog niet bestudeerd en als dusdanig ook nooit in aanmerking genomen voor het berekenen van de criminaliteit. Voor een integrale studie van de criminaliteit in het oud regime blijkt dit echter meer dan nodig.

Tenslotte lijkt het ons ook niet onbelangrijk om nog even te wijzen op het voortbestaan van het asielrecht of de kerkelijke immuniteit in de nieuwe tijd. Zoals hoger aangegeven, beriepen de Brugse kanunniken zich op dit eeuwenoude recht om Pieter van Wesemaele niet aan de Brugse magistraat te moeten uitleveren. Door dit asielrecht was het aan alle burgerlijke overheden verboden om zonder de toelating van de kerkelijke overheid een delinkwent op gewijde

25. M. FOUCAULT, Surveiller et punir, Parijs, 1975, p. 52 ; P. SPIERENBURG, De sociale functie van openbare strafvoltrekkingen, Centrum voor maatschappijgeschiedenis, E.H.R., Mededelingen, z.j. (1978) ; A. BLOK, Theatrische strafvoltrekkingen onder het Ancien Régime, Symposion, Tijdschrift voor maatschappijwetenschap, I (1979), P. 94-114.

26. Dit op grond van steekproeven die door ons werden gedaan op genadebrieven bewaard te Rijsel. RIJSEL, ARCHIVES DU NORD, B 1681-1824 ; C.H. PETITDUTAILLIS, Lettres de rémission de Philippe le Bon (Bibliothèque du XVe siècle, IX), Parijs, 1908 ; C. DEHAISNES, Etude sur les régistres des chartes de l'audience conservés dans l'ancienne chambre des comptes de Lille (XIVe-XVIIe s.), s.l., s.d. 
grond (kerk, kerkhof, klooster) aan de houden. Dit asielrecht dat in de middeleeuwen door de Kerk herhaaldelijk werd aangewend om de mechanische toepassing van het wereldlijke strafrecht te verhinderen en allerlei humane principes in het strafrecht te introduceren zoals het genaderecht ${ }^{27}$, werd in de $16 \mathrm{de}-17 \mathrm{de}$ eeuw door de Staat en zijn vertegenwoordigers, de legisten, als een relict van de irrationele middeleeuwse strafrechtspleging aangezien. Niet alleen verhinderde het een vlugge en daardoor efficiënte bestraffing, maar bovendien bleven hierdoor soms allerlei misdrijven ongestraft, wat volgens de Romeinsrechtelijk geschoolde penalisten die bezeten waren door de afschrikkingsgedachte, op zichzelf reeds criminogeen werkte. In de 16de en 17de eeuw, toen de Kerk ten gevolge van de godsdienstoorlogen overal moest inbinden ten voordele van de Staat, werden door deze laatste dan ook geleidelijk steeds meer stappen ondernomen om dit asielrecht in te perken. De verordeningen van 9 juli 1570 op de criminele justitie ${ }^{28}$ gevolgd door een verordening van 22 juni $1589^{29}$ sloten een aantal categorieën van zware misdadigers uit van dit asielrecht : landlopers, openbaar gekende dieven, straatrovers, moordenaars, kerkrovers, ketters, bankroetiers en zij die zich aan majesteitsschennis hadden schuldig gemaakt ${ }^{30}$. De Kerk aanvaardde deze maatregelen min of meer door het afkondigen van de bul «Cum alias nonnulli» van 1591 waarin bepaalde misdadigers van het asielrecht werden uitgesloten ${ }^{31}$. Het feit dat deze bul in de Nederlanden nooit werd geplaceteerd, de verschillende opsomming van de

27. Over dit asielrecht zie J.J.E. PROOST, Histoire $d u$ droit d'asile religieux en Belgique, Gent, 1870 ; P. HILDEBRAND, Uit de geschiedenis van het kerkelijk schuilrecht, Rechtskundig Weekblad, XVI (1952-1953), kol. 1129-1144 ; H.J. ELIAS, Kerk en Staat in de Zuidelijke Nederlanden onder de regering der aartshertogen Albrecht en Isabella (1598-1629), Antwerpen, 1931, p. 228-231.

28. Placcaerten van Vlaenderen, V, Gent, 1763, p. 195.

29. Verordening van 22 juni 1589, art. 22, Placc. Vl., II, p. 175.

30. Verordeningen van 7 oktober 1531 (Placc. Vl., I, p. 755) en 4 oktober 1540 (Placc. Vl., I, p. 768) bepaalden reeds dat zij die zich schuldig hadden gemaakt aan bedrieglijk bankroet niet meer konden genieten van de vrijheydt van om het even welke plaats. Verordeningen van 11 april 1541 (Placc. Vl., I, p. 19) en 18 september 1542 (Placc. Vl., I, p. 23) breidden deze maatregel uit tot de landlopers, brandstichters, brandschatters en alle openbaar gekende dieven. In deze verordeningen wordt niet duidelijk bepaald of met deze vrijheydt ook het kerkelijk schuilrecht werd bedoeld.

31. Placcaten ende ordonnantien van Brabandt, Antwerpen, 1648, I, p. 32-34. 
uitgesloten misdadigers in deze bul in vergelijking met de vorstelijke verordeningen en het feit dat beide soort teksten voor ruime interpretatie vatbaar waren, leidde op het einde van de 16de en in het begin van de $17 \mathrm{de}$ eeuw tot veel moeilijkheden tussen de kerkelijke en de wereldlijke overheden. Bovendien was men het er niet over eens welke rechtbank precies moest oordelen of een misdadiger die zijn toevlucht had genomen tot een gewijde plaats al dan niet van het asielrecht kon genieten. De Kerk eiste die recht op voor de kerkelijke rechter; de burgerlijke rechtbanken, met de justitieraden aan het hoofd, eisten dit recht voor zich op $^{32}$. In het geval van Pieter van Wesemaele waren er blijkbaar geen moeilijkheden tussen de Brugse kanunniken en de Brugse stadsmagistraat. De Brugse stadsmagistraat eiste weliswaar Pieter van Wesemaele terug op, maar deed geen pogingen om hem desnoods manu militari te vatten. Als dusdanig erkenden de Brugse stadsschepenen het asielrecht van de Brugse kanunniken alhoewel openbare dieven in de bul "Cum alias nonnulli» uitdrukkelijk van dit recht waren uitgesloten. Blijkbaar hielden zij zich strikt aan de vorstelijke verordeningen van 1570 en 1580 die dergelijke misdadigers van dit recht niet hadden uitgesloten. Gelukkig voor Pieter van Wesemaele, want de beul zou hoogstwaarschijnlijk niet voor een derde maal hebben gefaald.

32. Zie voorbeeld BRUSSEL, RIJKSARCHIEF, Rekenkamer, nr. 13.835, Baljuwsrekening Kortrijk 1602-1605, f. 16 $6^{v}-17^{r}$. 
BIJLAGE : Genadebrief voor Pieter van Wesemaele dd. 25 februari 1613

- BRUGGE, BISSCHOPPELIJK ARCHIEF, Register A 67, f. 175'-176r. ${ }^{1}$ Zie ook BRUGGE, STADSARCHIEF, 192 (Verluydboeck 1611-1676), $\mathrm{f}^{\circ} 16^{\mathrm{r}}-19^{\mathrm{r}}$.

Albert ende Isabel Clara Eugenia, Infante van Spaignen by der gratie Godts, Eertzhertoghen van Oostenrycke, hertoghen van Bourgoingnen, van Lotryck, van Brabant, van Lemborch, van Luxemborch, van Gueldren, Grave van Habsbourch, van Vlaendren, van Artois, van Bourgoingnen, van Tirol, Palsgraven ende van Henegauwen, van Hollandt, van Zeelandt, van Naemen ende van Zutphen, Marcgraven des heylich rycx van Roome, heere ende vrauwe van Vrieslandt, van Salins, van Mechelen, van der stadt, steden ende landen van Utrecht, Overyssel ende Groeninghe. Onze lieve ende beminde, de schouteden, burhmeesters, schepenen ende raedt onzer stede van Brugghe, saluyt. Wy hebben ontfanghen die oitmoedighe supplicatie ende requeste van Pieter van Wesemaele, ghebooren van Loockere binnen onzen lande van Waes, cleermaecker van zynen style, oudt ontrent XXIIIJ jaeren, inhoudende dat den suppliant duer zeker ghevecht gheinfligiert hebbende uuyt nootweere an een voerman int voornompt Landt van Waes een quetsuere, uuyt respect van justicie hem van daer heeft vertrocken binnen onze stadt van Ghendt ten huyse van de weduwe van Jan de Dyckere, alwaer hy uuyt vrientschap die zy tot zijn ouders was draghende ontfanghen zynde, heift dụer menschelicke crancheyt ende doccasie dat in zyn slaepcamer was staende zeeker ghesloten cofferkin, zo verre vergheten, dat hy tzelve forcelyck met zyn handen heeft openghedaen, ende daeruuyt ghenomen ontrent de dertich ponden grooten in gouden ghelde. Van welcken huyse vertrocken zynde naer Hollandt, es van daer weder ghecommen naer onze stadt van Brugghe, hem beghevende in dienst van den heere van Oyeghem, zuene van den jegenwoordighen schoutete der selver stede. In welcken dienst den tydt van ontrent neghen maenden ghecontinueert ende daerinne hem behoorlycke ghequeten hebbende, heeft zynen dienst verandert metten voornomden heere schoudt, binnen den zelven huuse als tsaemen wonende. Ende leden ontrent een jaer, ghesien hebbende dat zynen heere ende meester was legghende den slotel van zeker buffekten, staende in zyn comptoir op zeker plaetse, ende opcommende doccasie, dat hy daeruuyte gheroepen wierdt omme te spreken zeker persoon van qualiteyt, heeft duer middele van tselve slotelken uuyt tvoorseyde buffetken ghenomen de somme van XIJ libras grooten. Omme welcke onnuetelick te verteeren gheen ghenouchsaeme libertydt hebbende, heeft hem oock vervoordert buyten de wete van den voornomde zynen meester, te doen maecken eenen slotel van de voorduere ende omme daermede by nachte uuyt ende inne te gaene. Welcken slotele den suppliant, vertreckende uuyt den voorseyde 
dienst, heeft ooc buyten de wete van zynen voorseyde heere ende meester overghelevert an den dienaere van den voorseyde heere van Oyeghem. Van welcken dienaere den suppliant oock heeft ontfanghen de figuere van zeker slotelken ghedruckt in wasse, dienende tot het buffet van zynen meester daer ghelt in was. De welcke hy heeft ghevercht te doen maecken ende afstellen met intentie dat den voornoemde dienaere, zynen compaignon, daermede tghelt uuyt tvoornoemd buffet zoude nemen thuerlieder ghemeene proffyte, ende daer thenden ghesaemdelick uuyter stadt zouden trecken. Ter cause van al twelcken den suppliant by justicie aenghetast in de vanghenesse gheleyt ende aldaer gheweist zynde den tydt van eender maent, es endelynghe up den XVJen sproocle XVJ'XIIJ by ulieden verwesen gheweist ter doot metter coorde. Dewelcke ontfanghen hebbende, es aen het gherechte gheleyt, ende naerdien hy hem in de handen van den almoghende, ende zonderlynghe van de zuyver maghet Maria, singuliere uuytvercoren patronesse van den suppliant, hadde bevolen, es by den officier van de leere afgesteken gheweest, alwaer tusschen hemele ende aerde goeden tydt hebbende ghehanghen ende diversche pressuren ende spronghen by den officier ghedaen zynde, es de coorde int middel afghebroken ende den suppliant ter aerde deur het ghewelt van de voorseyde pressuren zeer hardt op de calceyen ghevallen, daerdeure overzulx zyn hooft zeere ghequetstses gheworden. En alzoo eenich schynsel ende apparentie van leven in den suppliant was openbaerende, zoo heift den officier hem voorts gheslipt van de plaetse van den val tot an de leere van tvoornomde gherechten, doende aen zynen hals eenen nieuwen bast, ende hem zoo woelende an de zelve leere dat men andere niet en heeft ghemeynt oft den suppliant en was ter doot ghebrocht. Waervooren hy overzulcx es gheleyt op een baere, ende ghedreghen op het kerchof van Sinte Donaes, omme aldaer begraven te worden in het graf twelcke daertoe was bereet. Zoo hy overzulcx in de aerde ghesteken zoude zyn gheweest, newaere datter noch drye andere naer hem hadden gheexecuteert gheweest om hemlieden alzoo ghesaemdelycke te begraven, zynde alsnu ghebeurt dat den suppliant ligghende aldus over doot, zyn lichaem heeft eenighen tydt daernaer beghinnen roeren, waerduere hy als ghebrocht zynde op de heylighe ghewyde aerde, es verdreghen in de voorseyde kercke, alwaer ten derder daeghe gheleghen hebbende, zyn memorie ende verstant weder eerst es ghecommen. By den welcken, ende dat hy suppliant de bitter doot deur middel alsvooren heeft ghesmaeckt ende publycquelyck in effecte justicie voldaen, waerdeure overzulcx het ghemeente, dwelcke in zeer groote ghetalle was aenziende de justicie ende het recht dat men over de suppliant was doende, heeft gheroepen ende ghebeden om gratie naerdien hy van de galghe alsvooren was ghevallen, twelcke den suppliant vastelycke betraut gheschiet te zyne door de voorspraecke van den heleghe moeder Gods Maria, dewelcke hy in de voornomden zynen uuytersten noodt zynde continuelyck hadde ghebeden met het lesen van een roosecransken, dat hem pater prior van de predicaren, zynen biechtvader, 
hadde ghegheven, ende twelcke hy hem voor het gherechte ghecommen zynde heeft gherestitueert. Soo eist dat den suppliant hem heeft tot ons ghekeert, biddende zeer oitmoedelyck dat ons ghelieven wille hem suppliant tghene voorseyt te vergheven ende hem te doen depescheren onze opene briefven van pardoene daertoe dienende. Zoo eist dat wy van tghene voorseyt ghehadt hebbende particulier rappoort, hebben omme redenen ons daertoe moverende, den suppliant vergheven ende quycteghescholden, vergheven ende schelden quycte uuyt onse zonderlynghe gratie mits desen de delicten ende mesusen by hem ghecommitteert ende omme dewelcke hy ten rechten by ulieden ter doot is verwesen. Ordonneren u daeromme ende bevelen ende alle anderen onsen rechteren, justicieren ende officieren, dat ghy den suppliant van teffect van dese onze gratie ende pardoene doet, laet ende ghedooght rustelick, vredelick ende vulcommelick ghenieten ende ghebruycken zonder hem te doen ofte laeten gheschieden eenich inder, letsel ofte moyennesse ter contrarien, want ons alzoo ghelieft. Ghegheven in onze stadt van Brussel desen laesten dach february int jaer ons heeren 1613. Onder stondt geschreven : By de Eert hertoghen in hunnen Raede. Ende onderteeckent : De la Faille, met den grooten zeghel in roode wasse uuthanghende.

1. Een bijzondere dank voor de heer L. Danhieux die ons de referentie van dit stuk doorgaf. 
